\title{
Receptor-interacting protein kinase 3-mediated programmed cell necrosis in rats subjected to focal cerebral ischemia-reperfusion injury
}

\author{
YANRU DONG ${ }^{1}$, CUIFEN BAO $^{2}$, JINGWEI YU ${ }^{1}$ and XIA LIU ${ }^{1}$ \\ ${ }^{1}$ Department of Histology and Embryology; ${ }^{2}$ Key Laboratory of Molecular Cell Biology and New Drug Development, \\ Liaoning Medical University, Jinzhou, Liaoning 121001, P.R. China
}

Received February 24, 2015; Accepted December 22, 2015

DOI: $10.3892 / \mathrm{mmr} .2016 .5311$

\begin{abstract}
In the current study, the activation of tumor necrosis factor- $\alpha$ receptor 1 (TNFR1) and receptor-interacting protein kinase 3 (RIP3) were investigated following cerebral ischemia-reperfusion injury (CIRI). Healthy SD rats were randomly divided into 3 groups: Sham operation group, model group and inhibitor group. The model group and inhibitor group were further divided into 4 subgroups of 6,12 , 24 and $72 \mathrm{~h}$ following CIRI. Using right middle cerebral artery embolization, the CIRI model was generated. To confirm that the CIRI model was established, neurological scores, TTC staining and brain water content measurements were conducted. Immunohistochemistry and western blotting were conducted to investigate the expression of TNFR1 and RIP3 in the cerebral cortex. It was observed that nerve cell necrosis occurred following $6 \mathrm{~h}$ of CIRI. The appearance of necrotic cells was gradually increased with increasing CIRI duration. TNFR1 and RIP3 were positively expressed following $6 \mathrm{~h}$ of CIRI. With increasing durations of CIRI, the protein expression levels of TNFR1 and RIP3 were significantly increased. Pre-administration with Z-VAD-FMK (zVAD) significantly increased the protein level of RIP3, however, had no effect on the levels of TNFR1, and was accompanied by a reduction in necrosis. In conclusion, RIP3-mediated cell necrosis was enhanced by caspase blockade zVAD and the function of zVAD was independent of TNFR1 signaling following IR.
\end{abstract}

Correspondence to: Dr Xia Liu, Department of Histology and Embryology, Liaoning Medical University, 40 Songpo Road, Linghe, Jinzhou, Liaoning 121001, P.R. China

E-mail: dongyanru530@163.com

Key words: Z-VAD-FMK, receptor-interacting protein kinase 3, tumor necrosis factor- $\alpha$ receptor 1 , cerebral ischemia-reperfusion injury, necrosis

\section{Introduction}

Ischemic cerebrovascular disease accounts for $60-80 \%$ of all cerebrovascular diseases (1). Compared with other forms of cerebrovascular disease, ischemic cerebrovascular disease is characterized by high incidence, high disability, high recurrence and high mortality, and poses a serious threat to human health. At present, thrombolytic therapy is the primary treatment strategy. However, the blood reperfusion of an ischemic injury frequently leads to further aggravation of the injury (2).

Previous studies have indicated that cerebral ischemia-reperfusion injury (CIRI) leads to the aggravation of injury factors, including free radicals, excitatory amino acids and calcium overload, and additionally correlates with ischemia-induced cerebral cell apoptosis and necrosis $(1,3,4)$. Apoptosis and necrosis of brain cells leads to various degrees of dysfunction amongst patients, and results in a heavy burden being placed upon the patient's family and society (5). Therefore, it is important to understand the mechanisms underpinning apoptosis and necrosis in CIRI.

Necrosis is an unprogrammed and therefore irreversible form of cell death (6). Therefore, previous treatment strategies of CIRI have predominantly focused upon the prevention of apoptosis. However, clinical practice has indicated that intervening in apoptosis is not an effective strategy for the prevention of CIRI (1). Increasing evidence indicates that certain forms of necrosis are regulated by cellular signaling pathways, including the tumor necrosis factor- $\alpha$ (TNF- $\alpha$ ) receptor 1 (TNFR1)-mediated programmed necrosis pathway (6). TNFR1 serves an important role in inflammatory responses, cell immunity and additional physiological and pathological processes (7). He et al (8) reported that receptor-interacting serine/threonine-protein kinase 3 (RIP3) is a key protein in TNF- $\alpha$-induced necrosis. RIP3 belongs to the RIP family, which has a high Ser/Thr specific protein kinase domain homology, with a conserved kinase domain in the N-terminus and a RIP homotypic interaction motif (RHIM) domain in the C-terminus (9). When caspase-8 (C-terminal) activation is inhibited, RIP3 is able to bind to RIP1 through the domain, thereby forming a cellular necrosis complex. However, when mutations occur in 4 amino acids of the RHIM domain, the interaction between RIP3 and RIP1 
is interrupted, thereby leading to the loss of function of RIP3 in necrosis (10-12). Therefore, RIP3 serves an important role in the cellular death pathways (9-13). Previous studies have demonstrated that embryonic fibroblast cells derived from RIP3-deficient mice exhibit resistance to TNF- $\alpha$-induced cell necrosis (8). In addition, in the caerulein-induced acute pancreatitis mouse model, RIP3 gene knockout significantly reduces necrosis of pancreatic cells and promotes the recovery of acute pancreatitis (14). Zhang DW suggested that upon the stimulation of necrotic signals, RIP3 proteins act as molecular switches for TNFR1-induced apoptosis and necrosis, and are required for necrosis $(15,16)$. However, the expression levels of RIP3 and TNFR1 following CIRI remains to be investigated.

In the current study, the expression of RIP3 and TNFR1 following CIRI were investigated using immunohistochemistry and western blotting. Furthermore, the effects and mechanisms of RIP3 and TNFR1 in cerebral cell necrosis were investigated. The current study may aid in the elucidation of the various programmed necrosis pathways involved following CIRI, and may increase understanding of the pathogenesis of ischemic encephalopathy, thus improving treatment strategies.

\section{Materials and methods}

Rat model of CIRI. The current study was conducted in accordance with the guidelines for The Care and Use of Animals in Research (17), and the protocols used were approved by the Liaoning Medical University Animal Care and Use Committee (Liaoning, China). Adult male Sprague-Dawley rats (Sibeifu Co., Beijing, China; $\mathrm{n}=40$ ) weighing $250 \pm 20 \mathrm{~g}$ were housed in an environmentally controlled room at Liaoning Medical University (Liaoning, China) $\left(22 \pm 2^{\circ} \mathrm{C}\right.$ with a $12 \mathrm{~h} / 12 \mathrm{~h}$ light/dark cycle). The rats were supplied with standard rat chow and water ad libitum. Focal cerebral ischemia was induced by middle cerebral artery occlusion (MCAO), as described previously (18) with modifications. Briefly, MCAO was conducted using an occluding suture (diameter, $0.26 \mathrm{~mm}$ ) for $2 \mathrm{~h}$, as follows. Rats were anesthetized with $10 \%$ chloral hydrate from Beijing Solarbio Science \& Technology Co., Ltd. (Beijing, China; $100 \mathrm{~g} / 0.3 \mathrm{ml}$ ) via intraperitoneal injection. The cutaneous operational area was cleaned regularly and a $2-3 \mathrm{~cm}$ incision was made in the skin of the neck. The right common carotid artery, the external carotid artery and the internal carotid artery were isolated. The external carotid artery was ligated, blood flow was blocked and a 4-0 monofilament (Beijing Solarbio Science \& Technology Co., Ltd.) with a blunted tip coated with poly-L-lysine (Beijing Solarbio Science $\&$ Technology Co., Ltd.) was inserted into the internal carotid artery through the external carotid artery. The suture was advanced $\sim 18-20 \mathrm{~mm}$ beyond the carotid artery bifurcation until the origin of the middle carotid artery was blocked. Following $2 \mathrm{~h}$ of MCAO-evoked ischemia, the suture was slowly drawn back to allow reperfusion. The reperfusion durations were 6 , 12, 24 and $72 \mathrm{~h}(\mathrm{n}=6,6,16$ and 6 , respectively). The suture was not inserted into the sham operation group $(n=6)$. Rectal temperature was maintained throughout the procedure at $37 \pm 0.5^{\circ} \mathrm{C}$ with a temperature-regulated heating pad.

Rat groups and treatments. Rats were randomly divided into the following three groups ( $n=16$ rats/group): i) Sham group,
$\mathrm{S}(\mathrm{n}=6)$; ii) MCAO model group received saline treatment, IR $(n=6,6,16$ and 6 for $6,12,24$ and $72 \mathrm{~h}$ reperfusion, respectively); iii) MCAO model group received the caspase inhibitor Z-VAD-FMK (zVAD; Sigma-Aldrich, St. Louis, MO, USA) treatment 1 day prior to MCAO operation, IR+I. Rats in the IR group received MCAO for $2 \mathrm{~h}$, followed by reperfusion for $6,12,24$ and $72 \mathrm{~h}$. Rats in the $\mathrm{S}$ group underwent the same surgical procedures as those in the IR group, however the suture was not advanced beyond the internal carotid bifurcation. No additional treatments were given in the $\mathrm{S}$ group and IR group. Animals in the IR + I group received an intraperitoneal injection of the caspase inhibitor (zVAD; $2 \mathrm{mg} / \mathrm{kg}$ ) 1 day prior to MCAO.

Neurological evaluation. Rats were examined for neurological deficits following MCAO by two investigators who were blinded to the groups, using a 5-point neurological function score: 0 , no deficit; 1 , failure to extend right forepaw fully; 2 , circling to the right; 3 , falling to the right; 4 , no spontaneous walking with a depressed level of consciousness. Only rats exhibiting no or incomplete forelimb placing with rotational asymmetry following MCAO were included in the subsequent analysis (19).

Edema measurement. Rats from each group $(\mathrm{n}=5)$ were decapitated under deep anesthesia with $10 \%$ chloral hydrate at $6,12,24$ and $72 \mathrm{~h}$ of reperfusion. The ipsilateral and contralateral hemispheres were dissected and the wet weight of the tissue was measured. The tissues were dried at $120^{\circ} \mathrm{C}$ for $24 \mathrm{~h}$. The percentage of cerebral water was determined as: (wet weight - dry weight)/dry weight x 100.

Infarct measurement. Following reperfusion, rat brains ( $n=5$ from each group) were removed and frozen at $-80^{\circ} \mathrm{C}$ for $5 \mathrm{~min}$. Coronal slices $(2 \mathrm{~mm})$ were made using a rodent brain matrix (HEAD Biotechnology Co,. Ltd., Beijing, China). The sections were stained for $20 \mathrm{~min}$ at $37^{\circ} \mathrm{C}$ with 2\% 2,3,5-triphenyltetrazolium chloride monohydrate (TTC; Sigma-Aldrich) and were then fixed with $4 \%$ formaldehyde. The infarct volume was calculated as previously described (20). In brief, the sections were scanned and the infarct area in each section was calculated by subtracting the noninfarct area of the ipsilateral side from the area of the contralateral side using ImageJ analysis software (version 1.46; National Institutes of Health, Bethesda, MD, USA). The infarct areas of each section were summed and multiplied by section thickness to give the total infarction volume.

Hematoxylin and eosin $(H \& E)$ staining. $H \& E$ histology was conducted at $6,12,24$ and 72 h following reperfusion. Rats were anesthetized by an intraperitoneal injection of $10 \%$ chloral hydrate $(100 \mathrm{~g} / 0.3 \mathrm{ml})$ and then perfused transcardially with saline (Beijing Solarbio Science \& Technology Co., Ltd.; $250 \mathrm{ml}$ ), followed by $4 \%$ formaldehyde (Beijing Solarbio Science \& Technology Co., Ltd.; $250 \mathrm{ml}$ ). Brains were removed and fixed in $4 \%$ formaldehyde at $4{ }^{\circ} \mathrm{C}$ for $72 \mathrm{~h}$ and then dehydrated and embedded in paraffin blocks (Beijing Solarbio Science \& Technology Co., Ltd.). Coronal sections were cut posterior to the optic chiasma, at a thickness of $3 \mathrm{~mm}$. The sections were deparaffinized and hydrated with reducing 
concentrations of alcohol, stained with H\&E (Beijing Solarbio Science \& Technology Co., Ltd.) and photographed using an optical microscope (Axio Scope.A1; Zeiss AG, Oberkochen, Germany).

Immunohistochemical staining. Rat brains were removed, post-fixed in $4 \%$ formaldehyde overnight at $4{ }^{\circ} \mathrm{C}$ and cryoprotected with $30 \%$ sucrose in PBS. Brains were cut into coronal sections $(5 \mu \mathrm{m})$ using a Leica RM2135 microtome (Leica Microsystems GmbH). Sections were obtained from each rat, and the free-floating method was used for avidin-biotin-peroxidase labeling. Coronal sections were rinsed with PBS and treated with $0.3 \% \mathrm{H}_{2} \mathrm{O}_{2}(\mathrm{v} / \mathrm{v})$ in PBS for $10 \mathrm{~min}$ at room temperature to quench endogenous peroxidase. Following washing with PBS, sections were incubated with a blocking solution [10\% normal goat serum (Beijing Zhongshan Jinqiao Biological Technology Co., Ltd., Beijing, China), 0.3\% Triton X-100 (Beijing Solarbio Science \& Technology Co., Ltd.) in PBS] for $30 \mathrm{~min}$ at $37^{\circ} \mathrm{C}$. The slices were incubated with polyclonal anti-TNFR1 mouse monoclonal antibodies (1:200; cat no. sc-374185; Santa Cruz Biotechnology, Inc., Dallas, TX, USA) and polyclonal anti-RIP3 rabbit IgG antibodies (1:200; cat no. sc-135170; Santa Cruz Biotechnology, Inc.) for $1 \mathrm{~h}$ at $37^{\circ} \mathrm{C}$, followed by overnight incubation at $4^{\circ} \mathrm{C}$. Following rinsing, sections were incubated with goat anti-rabbit IgG antibodies (1:200; cat no. SAB4600015-50UL, Sigma-Aldrich) for $1 \mathrm{~h}$ at $37^{\circ} \mathrm{C}$. The antibodies were detected using $0.05 \%$ diaminobenzidime tetrachloride (Shanghai Kuaibo Biotechnology Co., Ltd., Shanghai, China) and $0.03 \% \mathrm{H}_{2} \mathrm{O}_{2}$ in PBS (pH 7.4). Images were captured using an optical microscope (Axio Scope.A1; Zeiss AG) at a magnification of $\mathrm{x} 40$, using a standard procedure. PBS was used as the negative control for the primary antibody. Positive cells were counted using a CIAS-1000 cell image analysis system (CIAS-1000, Zhongguo Hengda, Ltd., Beijing, China). All imaging was conducted with equal interval sections, ( 3 serial sections were taken and analyzed from each animal) and within each section, 2 non-overlapping high-power images (magnification, $x 400$ ) were obtained of the cerebral cortex. The protein expression positive cell number was counted from each perspective.

Western blotting. For western blot analysis, $15 \mathrm{mg}$ brain tissue was treated with $1 \mathrm{ml}$ radioimmunoprecipitation assay buffer containing $50 \mathrm{mM}$ Tris/ $\mathrm{HCl}(\mathrm{pH} 7.4), 150 \mathrm{mM} \mathrm{NaCl} 1 \%(\mathrm{v} / \mathrm{v})$ NP-40, $0.1 \%(\mathrm{w} / \mathrm{v})$ sodium dodecyl sulfate (SDS), $1 \%(\mathrm{v} / \mathrm{v})$ phenylmethylsulfonyl fluoride (all purchased from Beijing Solarbio Science \& Technology Co., Ltd.), $0.3 \%$ (v/v) protease inhibitor and $0.1 \%(\mathrm{v} / \mathrm{v})$ phosphorylated proteinase inhibitor (Sigma-Aldrich). The supernatants were then extracted from the lysates following centrifugation at $13,000 \mathrm{~g}$ at $4^{\circ} \mathrm{C}$ for $15 \mathrm{~min}$. To quantify the relative concentration of the total proteins, a bicinchoninic protein assay kit (Pierce Biotechnology, Inc., Rockford, IL, USA) was used. Subsequently, equal amounts of protein $(15 \mu \mathrm{g})$ were separated on an SDS-polyacrylamide gel electrophoresis gel [10\% (v/v) polyacrylamide] and transferred onto a polyvinylidene fluoride membrane (all purchased from Merck Millipore, Darmstadt, Germany) at $300 \mathrm{~mA}$ for $2 \mathrm{~h}$. To block nonspecific binding, the membrane was incubated with $8 \%$ (w/v) milk in Tris-buffered saline Tween-20 (Beijing Solarbio Science \& Technology Co., Ltd.) for $2 \mathrm{~h}$ at room temperature. The membranes were then incubated with primary antibodies against $\beta$-actin mouse $\mathrm{mAb}(1: 4,000$; cat no. 3700), RIP3 rabbit mAb (1:1,000; cat no. 15828) and TNFR1 rabbit mAb (1:1,000; cat no. 13377) all purchased from Cell Signaling Technology, Inc., Danvers, MA, USA) overnight at $4^{\circ} \mathrm{C}$. Subsequently, the membranes were washed with PBS-Tween 4 times ( $5 \mathrm{~min} / \mathrm{time})$. Membranes were then incubated with horseradish peroxidase-conjugated goat anti-rabbit IgG (1:5,000, Cell Signaling Technology, Inc.) for $2 \mathrm{~h}$ at room temperature. Following incubation, the membranes were washed 4 times ( $5 \mathrm{~min} / \mathrm{time}$ ). Proteins were detected using enhanced chemiluminescence (EMD Millipore, Billerica, MA, USA) according to the manufacturer's instructions, and the relative protein levels were determined. To measure the alterations in protein expression, target proteins were normalized to $\beta$-actin.

Statistical analysis. All values are presented as the mean \pm standard deviation. Data were analyzed for significance using the nonparametric Mann-Whitney U-test or analysis of variance using SPSS software, version 13.0 (SPSS, Inc., Chicago, IL, USA). $\mathrm{P}<0.05$ was considered to indicate a statistically significant difference.

\section{Results}

ZVAD increases the volume of cerebral infarction post-reperfusion. Infarct volume as a measure of stroke severity was first determined in the three rat groups (S group, IR group and IR + I group). In the IR group, the volume of the infarct region was significantly increased compared with the $\mathrm{S}$ group at 6, 24 and $72 \mathrm{~h}$, as assessed by TTC staining (Fig. 1A and B). To investigate whether zVAD enhances the infarct volume resulting from MCAO, $2 \mathrm{mg} / \mathrm{kg}$ zVAD or saline was administered intraperitoneally $10 \mathrm{~min}$ prior to the initiation of MCAO (or sham MCAO). Administration of zVAD increased the infarct volume in rat brains by 0.15 , 0.18 and $0.25 \%$ respectively at 6,24 and $72 \mathrm{~h}$ post-reperfusion $(\mathrm{P}<0.05$; Fig. 1). These results demonstrated the pro-necrotic effect of zVAD against CIRI.

zVAD enhances neurological deficit scores post-reperfusion. In the $\mathrm{S}$ group, no rats exhibited symptoms of neurological deficits, while there were clear neurological deficits in the IR group. In addition, the neurological function was significantly enhanced in the IR + I group rats at 24 and $48 \mathrm{~h}$ post-reperfusion compared with the sham group $(\mathrm{P}<0.05$; Fig. 2).

zVAD increases brain edema post-reperfusion. As presented in Fig. 3, brain edema was significantly increased post-reperfusion in the IR group. To investigate the function of zVAD, it was administered intravenously $10 \mathrm{~min}$ prior to the initiation of MCAO. The water content of the ischemic brains was significantly increased at $6,12,24$ and $72 \mathrm{~h}$ post-reperfusion ( $\mathrm{P}<0.05$; Fig. 3 ).

Evaluation of cerebral histology by $H \& E$. H\&E staining (Fig. 4) was conducted to investigate the histopathological alterations occurring following focal ischemia. Normal cells in 
A

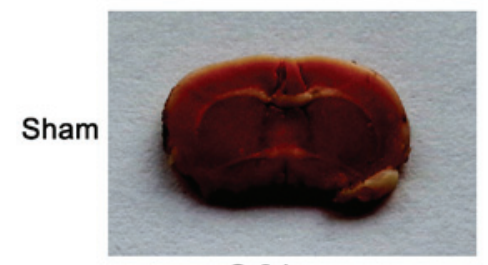

$\mathrm{S} 6 \mathrm{~h}$

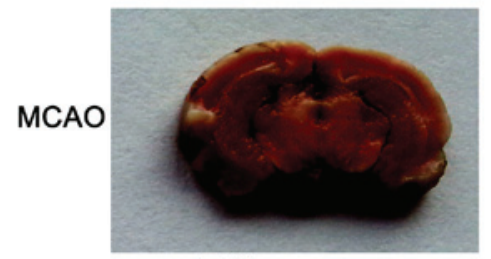

IR 6h

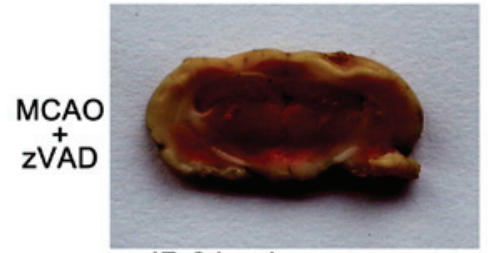

IR $6 \mathrm{~h}+$ I

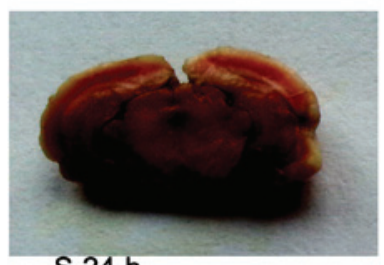

S $24 \mathrm{~h}$

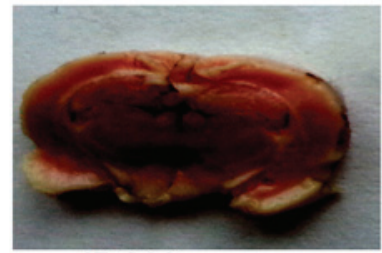

IR $24 \mathrm{~h}$

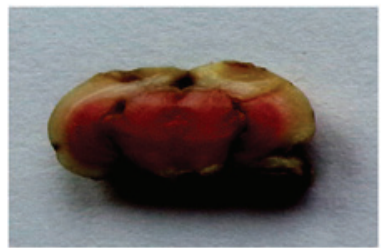

IR $24 \mathrm{~h}+$ I

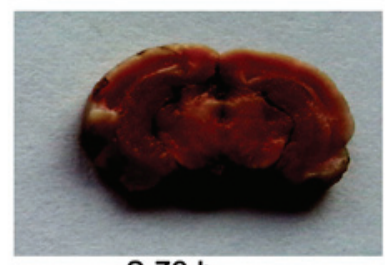

S $72 \mathrm{~h}$

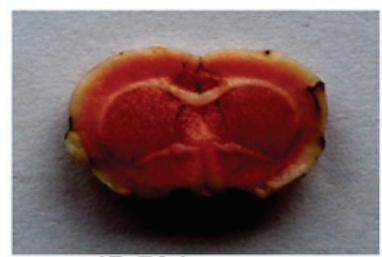

IR 72 h

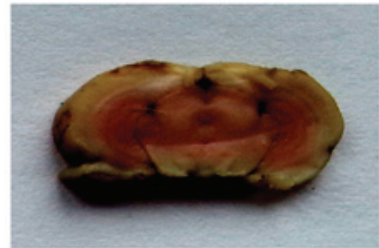

IR $72 \mathrm{~h}+$ I

B

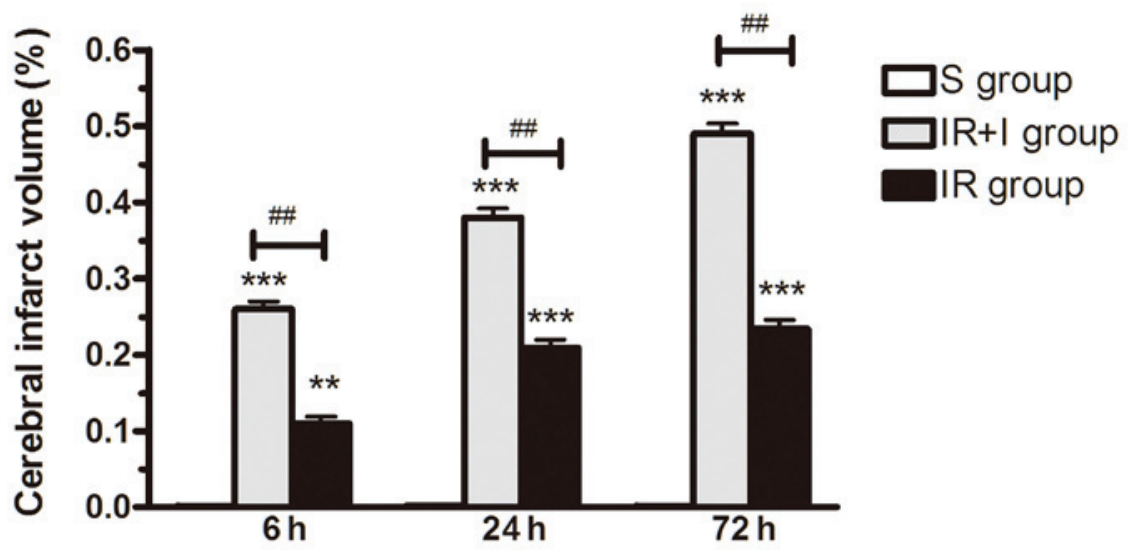

Figure 1. Measurement of infarct volume in cerebral ischemia-reperfusion injury model rats. (A) 2,3,5-triphenyltetrazolium chloride monohydrate-stained brain sections indicating the ischemic region (white) and the infarct area (red). (B) Infarct volume in the three experimental groups. Values ( $\mathrm{n}=6$ animals/group) are presented as the mean \pm standard deviation. ${ }^{* *} \mathrm{P}<0.01$ vs. $\mathrm{S}$ group; ${ }^{* * *} \mathrm{P}<0.001$ vs. IR group; ${ }^{\# \#} \mathrm{P}<0.01$ vs. IR group. $\mathrm{S}$, sham; IR, ischemia-reperfusion; I, z-fluoromethylketone.

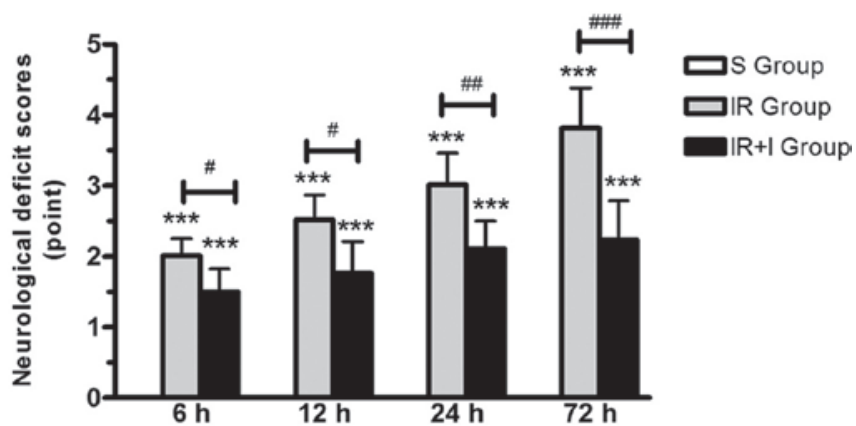

Figure 2. Neurological outcomes assessed by the 5-point neurological function score. The IR + I group demonstrated significant enhancement in neurological function compared with IR group. Values ( $n=6$ animals/group) are presented as the mean \pm standard deviation. ${ }^{* * *} \mathrm{P}<0.001$ vs. $\mathrm{S}$ group; ${ }^{\#} \mathrm{P}<0.05$ vs. IR group; ${ }^{\# \#} \mathrm{P}<0.01$ vs. IR group; ${ }^{\# \# "} \mathrm{P}<0.001$ vs. IR group. IR $+\mathrm{I}$, ischemia-reperfusion $+\mathrm{z}$-fluoromethylketone; $\mathrm{S}$, sham.

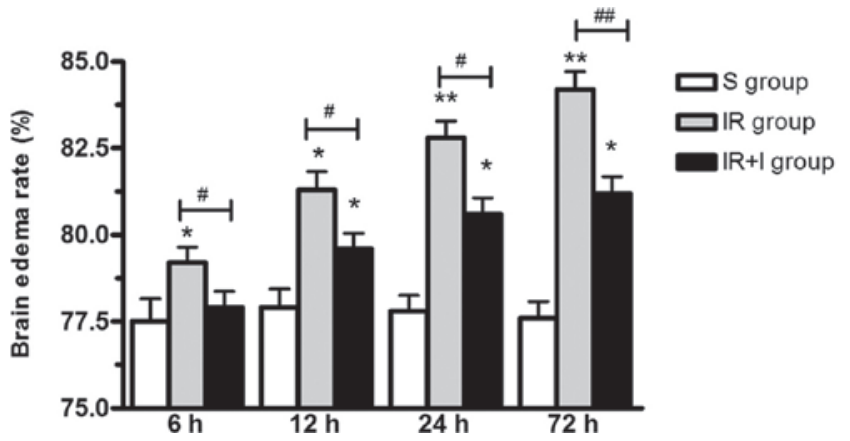

Figure 3. zVAD increases brain edema following focal cerebral ischemia. Edema in the IR group was significantly greater compared with the $\mathrm{S}$ group. zVAD significantly reduces brain edema following focal cerebral ischemia. Values ( $\mathrm{n}=6$ animals/group) are presented as the mean \pm standard deviation. ${ }^{*} \mathrm{P}<0.05$ vs. $\mathrm{S}$ group; ${ }^{* *} \mathrm{P}<0.01$ vs. $\mathrm{S}$ group; ${ }^{\#} \mathrm{P}<0.05$ vs. IR group; ${ }^{\#} \mathrm{P}<0.01$ vs. IR group. zVAD, z-fluoromethylketone; IR, ischemia-reperfusion; S, sham; I, z-fluoromethylketone. 
A

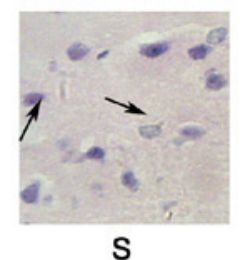

B

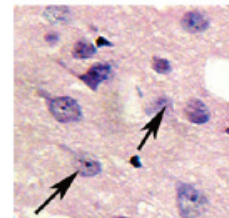

IR $6 \widehat{\mathrm{h}}+\mathrm{I}$

C

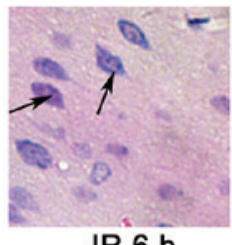

IR $6 \mathrm{~h}$

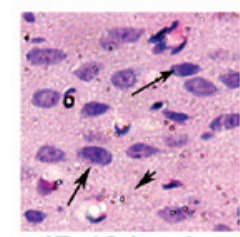

IR $12 \mathrm{~h}+$ I

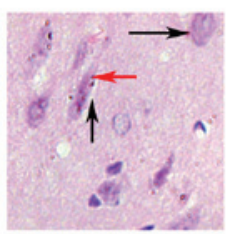

IR $12 \mathrm{~h}$

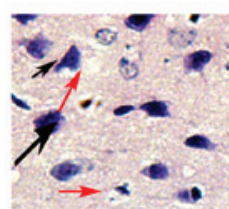

IR $24 \mathrm{~h}+$ I

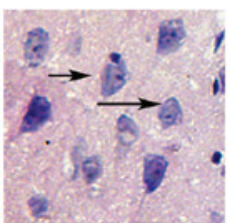

IR $24 \mathrm{~h}$

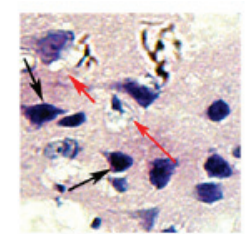

IR $72 \mathrm{~h}+$ I

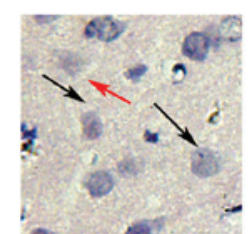

IR $72 \mathrm{~h}$

Figure 4. Evaluation of histopathological alterations in the ischemic penumbra and the core zone by H\&E staining. (A-C) H\&E staining presenting gross histopathological alterations in normal, ischemic penumbra and the ischemic core at 12,24 and $72 \mathrm{~h}$ post-reperfusion in the three groups. Black arrows indicate nuclear shrinkage, and the red arrows indicate neuronal vacuolization. Magnification, $\mathrm{x} 300$. Scale bar $=50 \mu \mathrm{m}$. H\&E, hematoxylin and eosin; $\mathrm{S}$, sham; IR, ischemia-reperfusion; I, z-fluoromethylketone.

A

C

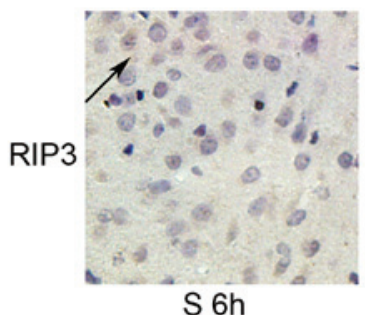

B

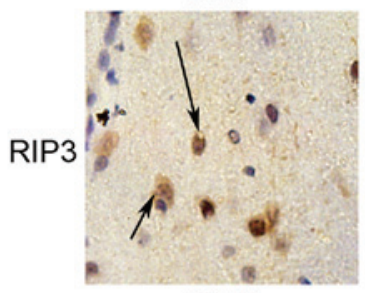

IR 6h

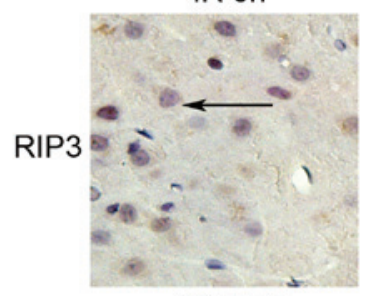

IR $6 \mathrm{~h}+$ I

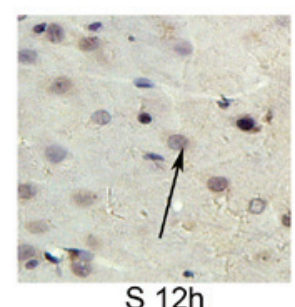

$\mathrm{S} 12 \mathrm{~h}$

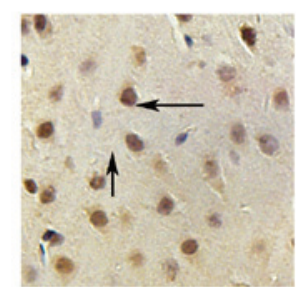

IR 12h

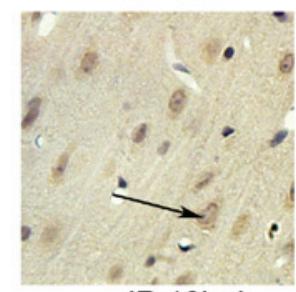

IR $12 \mathrm{~h}+$ I

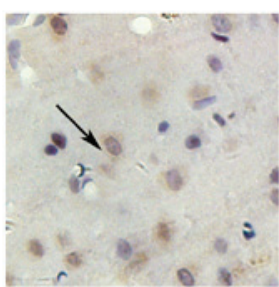

S 24h

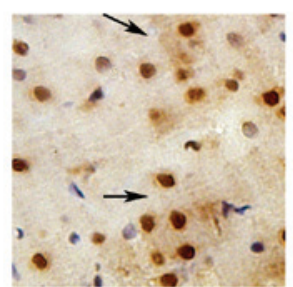

IR 24h

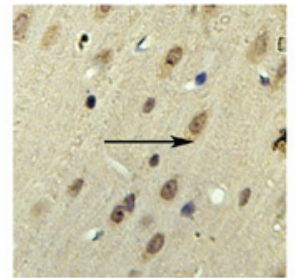

IR $24 h+$ I

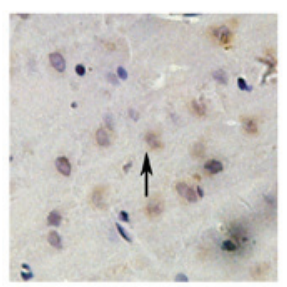

$\mathrm{S} 72 \mathrm{~h}$

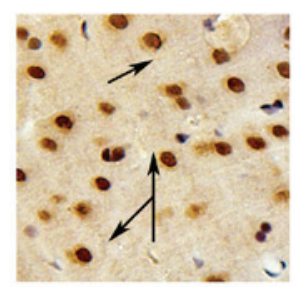

IR 72h

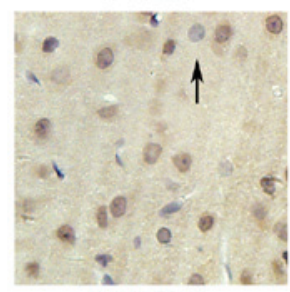

IR $72 h+1$

D

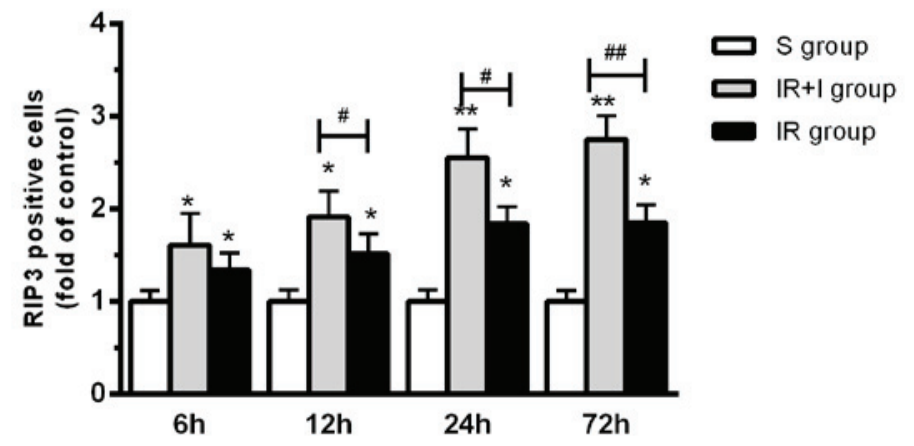

Figure 5. zVAD upregulates RIP3 protein expression levels in rat brain cortex. (A) S group rats at 6, 12, 24 and 72 h. (B) IR group. (C) IR+I group. zVAD upregulates RIP3 protein expression levels in rat brain cortex. Magnification, x100. (D) Quantification of RIP3 positive cells in the three groups. Values (n=6 animals/group) are presented as the mean \pm standard deviation. ${ }^{*} \mathrm{P}<0.05$ and ${ }^{* *} \mathrm{P}<0.01$ vs. $\mathrm{S}$ group; ${ }^{*} \mathrm{P}<0.05$ and ${ }^{\# \#} \mathrm{P}<0.01$ vs. IR group. zVAD, z-fluoromethylketone; RIP3, receptor-interacting protein kinase 3; S, sham; IR, ischemia-reperfusion; IR+I, ischemia-reperfusion + zVAD. 
A

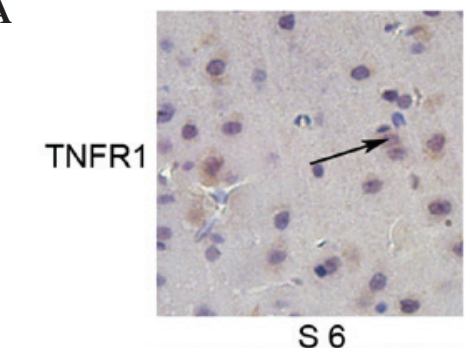

B

TNFR1

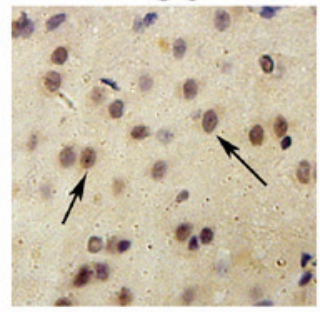

IR $6 \mathrm{~h}$

C

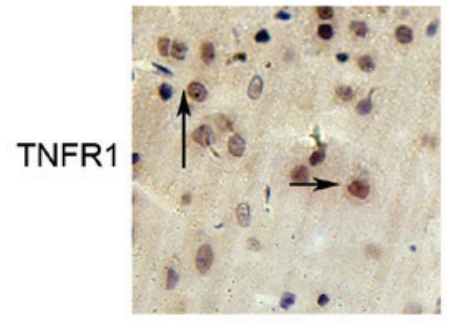

IR $6 \mathrm{~h}+$ I

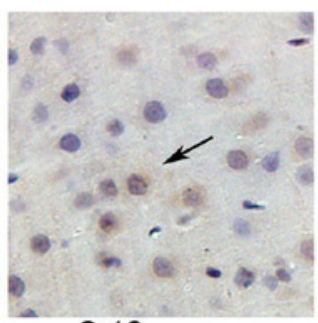

S 12

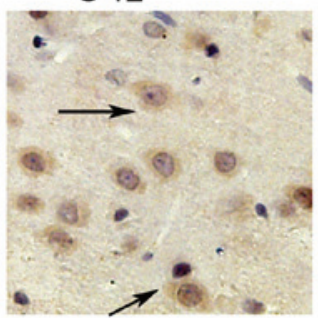

IR $12 \mathrm{~h}$

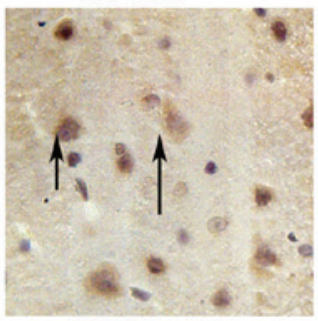

IR $12 \mathrm{~h}+$ I

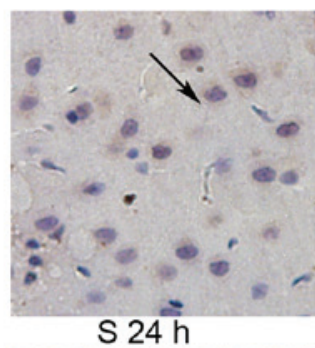

$\mathrm{S} 24 \mathrm{~h}$

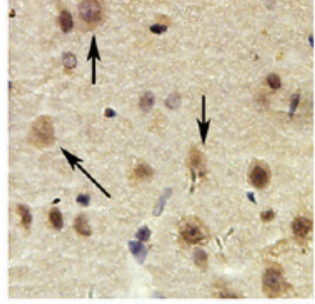

IR $24 \mathrm{~h}$

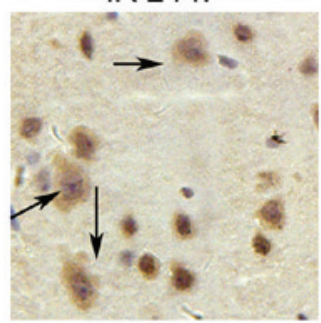

IR $24 \mathrm{~h}+$ I

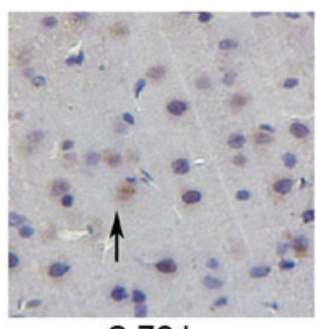

$\mathrm{S} 72 \mathrm{~h}$

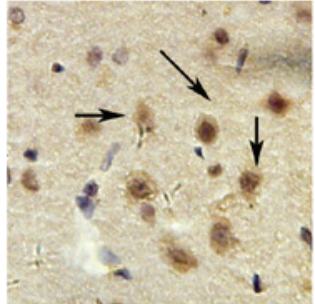

IR $72 \mathrm{~h}$

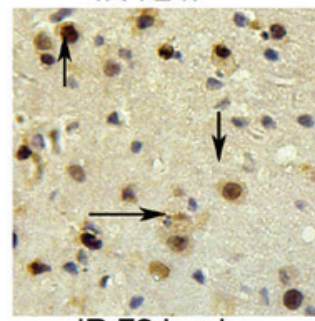

IR $72 \mathrm{~h}+$ I

D

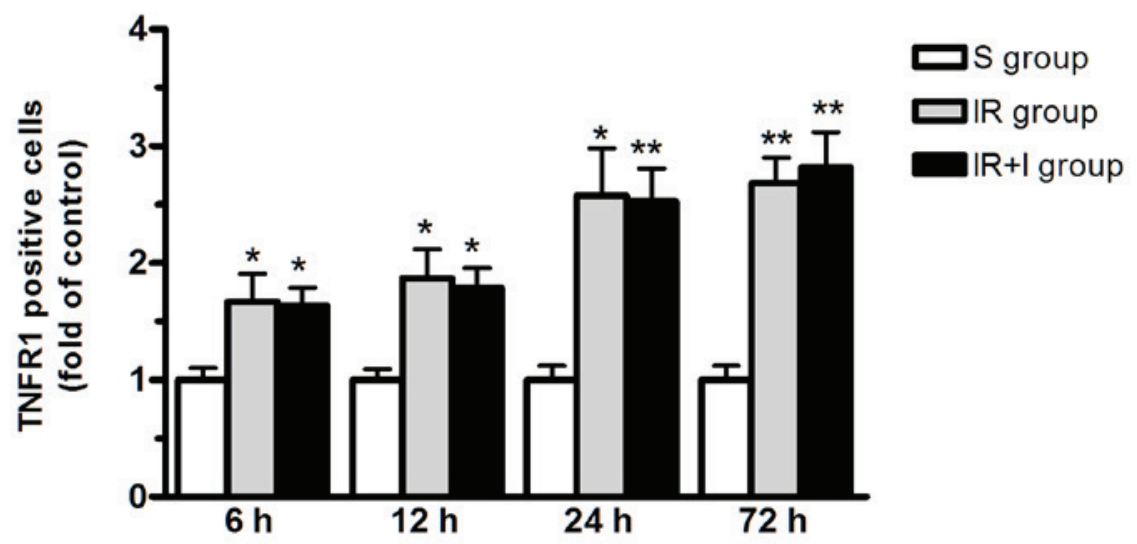

Figure 6. zVAD does not alter the TNFR1 protein expression level in rat brain cortex. (A) S group rats at 6, 12, 24 and $72 \mathrm{~h}$. (B) IR group. (C) IR+I group. (D) Quantification of TNFR1 positive cells in the three groups. Magnification, $x 100$. Values ( $\mathrm{n}=6$ animals/group) are presented as the mean \pm standard deviation. "P<0.05 vs. S group; ${ }^{* *} \mathrm{P}<0.01$ vs. S group. zVAD, z-fluoromethylketone; TNFR1, tumor necrosis factor- $\alpha$ receptor 1; S, sham; IR, ischemia-reperfusion; IR+I, ischemia-reperfusion + zVAD.

the contralateral hemisphere had round, lightly stained nuclei (Fig. 4A), whereas dying cells in the ipsilateral hemisphere had pyknotic nuclei (black arrows; Fig. 4B and C). In addition, dying cells exhibited signs of vacuolization (red arrows, Fig. 4B and C) in the core ischemic zone and the ischemic penumbra at 24 and $72 \mathrm{~h}$ following reperfusion. However, the pyknotic nuclei were significantly increased in the IR + I group rats at $6,12,24$ and $72 \mathrm{~h}$ post-reperfusion compared with the saline group $(\mathrm{P}<0.05$; Fig. 4B).

zVAD upregulates the expression levels of RIP 3 in the rat brain cortex. It has been previously reported that the expression levels of RIP3 were increased in the cortex following reperfusion and $2 \mathrm{~h}$ ischemia (20), which was in accordance with the findings of the present study (Fig. 5A). Compared with the saline groups, pretreatment with zVAD significantly increased the protein expression level of RIP3 in the IR + I group (Fig. 5B).As presented in Fig. 5C, enhanced RIP3 immunostaining was observed in cells scattered throughout the ischemic cortex $6,12,24$ and $72 \mathrm{~h}$ post-reperfusion. Quantification of RIP3 positive cells in the three groups are displayed in Fig. 5D.

zVAD does not alter TNFR1 protein expression levels in the rat brain cortex. As presented in Fig. 6, TNFR1 protein was expressed in the plasma membrane. The expression level of TNFR1 were significantly upregulated in the ischemic hemisphere at $6,12,24$ and $72 \mathrm{~h}$ post-reperfusion. However, zVAD does not alter the TNFR1 protein expression levels in the rat brain cortex (Fig. 6). 
A

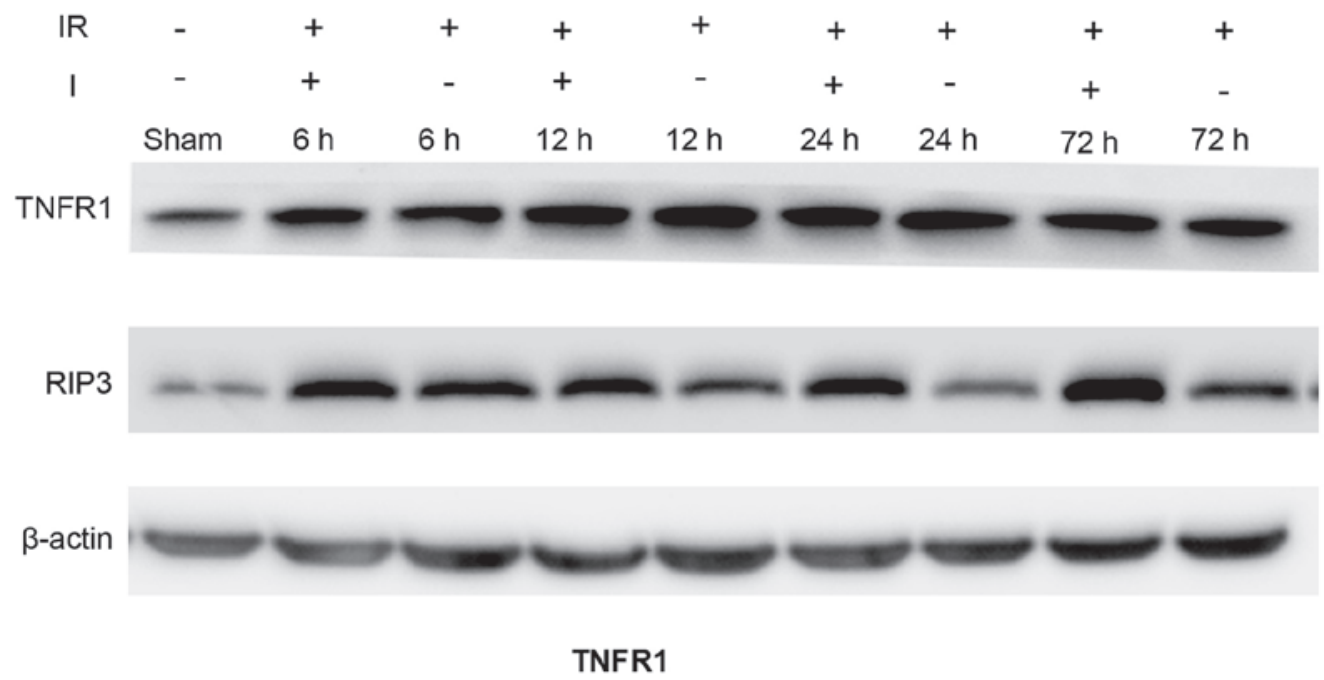

B

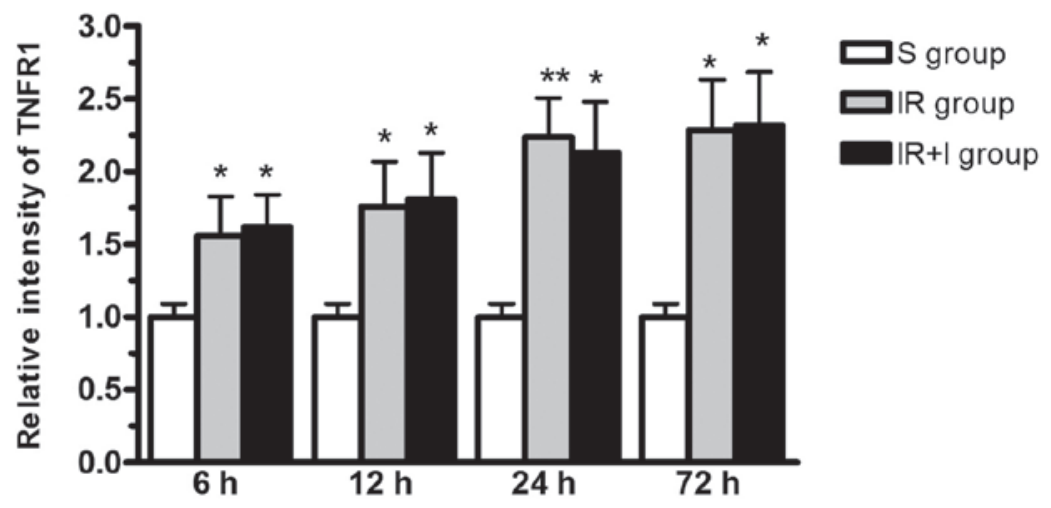

C

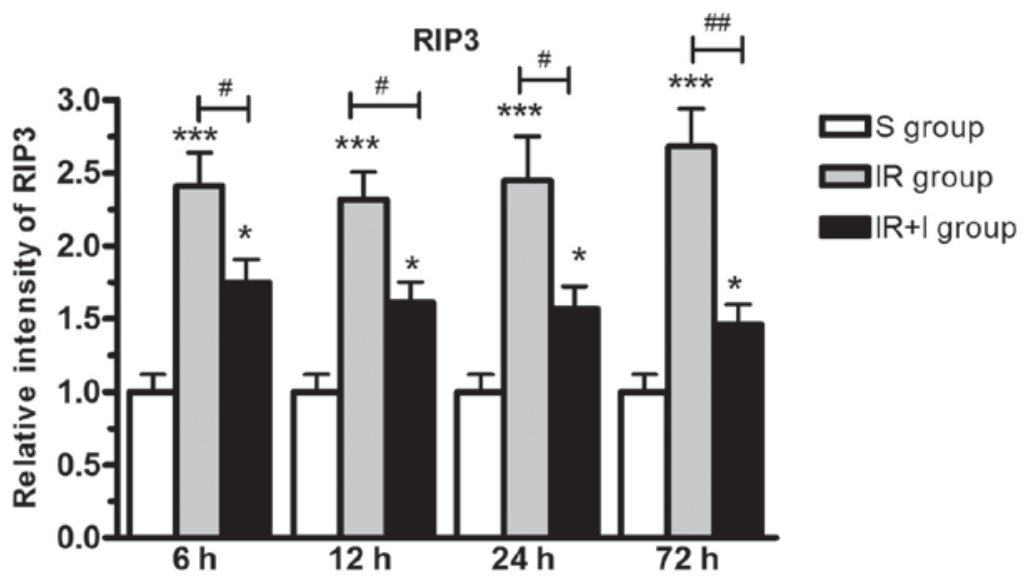

Figure 7. Western blot analysis of TNFR1 and RIP3 protein expression in the lesion boundary zone of the ipsilateral hemisphere. (A) Western blot images of TNFR1 and RIP3 expression. Relative intensity of (B) TNFR1 and (C) RIP3, in each of the three rat groups. Relative intensity is defined as the intensity of the target protein normalized to $\beta$-actin. Values ( $\mathrm{n}=6$ animals/group) are presented as the mean \pm standard deviation. ${ }^{*} \mathrm{P}<0.05$ vs. $\mathrm{S}$ group; ${ }^{* *} \mathrm{P}<0.01$ vs. $\mathrm{S}$ group; ${ }^{* * * *} \mathrm{P}<0.001$ vs. $\mathrm{S}$ group; ${ }^{\#} \mathrm{P}<0.05$ vs. IR group; ${ }^{\# \#} \mathrm{P}<0.01$ vs. IR group. TNFR1, tumor necrosis factor- $\alpha$ receptor 1 ; RIP3, receptor-interacting protein kinase 3 ;

$\mathrm{S}$, sham; IR, ischemia-reperfusion; IR+I, ischemia-reperfusion + z-fluoromethylketone.

Protein expression levels of RIP3 and TNFR1 in the lesion boundary zone of the ipsilateral hemisphere. To further investigate the effect of zVAD on the expression of RIP3 and TNFR1, western blotting was used to measure target protein levels in the lesion boundary zone in the three rat groups. The western blotting data (Fig. 7) supported the immunohistochemical data (Figs. 5 and 6), in that the protein expression levels of RIP3 and TNFR1 were significantly greater in the IR group compared with the $\mathrm{S}$ group $(\mathrm{P}<0.05)$.
RIP3 was expressed at greater levels in the IR + I group, while no significant alterations were observed in TNFR1 levels (Fig. 7).

\section{Discussion}

As a fundamental cellular process, programmed cell death widely regulates cell proliferation and homeostasis. Previous studies have indicated two important cellular death pathways, 
including apoptosis and programmed necrosis (21). To the best of our knowledge, the role of necrosis in CIRI remains to be fully elucidated. In the current study, RIP3-mediated cell necrosis was enhanced by caspase blockade using zVAD, and the function of zVAD was observed to be independent of TNFR1 signaling. The current study is the first to demonstrate the effect of zVAD in rat brains using a model of transient MCAO. In addition to enhanced structural injury, a reduction in neurological outcomes was observed, furthermore zVAD increased infarct size and brain edema following reperfusion.

Over $80 \%$ of stroke cases result from ischemic stroke, which is characterized by high morbidity and mortality (22). Following a period of ischemia, reperfusion damage may occur when blood flow resumes in the brain (23), and reperfusion serves an important role in the pathology of cerebral ischemia (24). Numerous studies report the correlation between certain pathologies and CIRI, including brain edema, inflammation, apoptosis and necrosis (25-27).

Apoptosis is an important cellular process in the maintenance of homeostasis in all tissues. Caspases belong to the cysteine protease family and serve key roles in the initiation of apoptosis (28). Caspase- 8 is considered to be an initiator caspase and therefore is critically involved in apoptosis (29). Upon the stimulation of TNF-like cytokines, death receptors are triggered and the caspase cascade is activated, leading to apoptotic cell death (30). Previous studies have indicated that the inhibition of caspase activity by specific caspase inhibitors, such as zVAD, is able to lead to apotosis-independent cell death, namely programmed necrosis (necroptosis) (31-33). Necroptosis has been demonstrated to be regulated by two key kinases, RIP1 and RIP3 (29).

RIP1 and RIP3 are suggested to serve key roles in TNF-induced cell necrosis $(8,11,16)$. Previous studies have indicated that the binding of TNF-like death cytokines to TNFR1 triggers the formation of a large protein complex, including TNFR1-associated death domain protein, TNF receptor-associated factor 2 and RIP1 (34). It has been reported that necrosis is initiated by RIP1 and RIP3 following the activation of death receptors (35). RIP3 belongs to the RIP family, which has homologs to RIP1, RIP2 and RIP4 $(36,37)$. However, the C-terminal domain of RIP3 is significantly different from other RIPs $(36,37)$. Transient overexpression of RIP3 in certain cells has been demonstrated to induce cell death (36).

Following the induction of necrosis, RIP3 is recruited to RIP1 and constitutes a necroptosis-inducing complex. It has been suggested that RIP3 functions as a molecular switch for necrosis (14). Previous studies have demonstrated that knockout of RIP3 is able to promote cell survival even in the lethal phenotype of caspase- 8 deficient mice $(12,38)$. In addition, studies have reported that caspase- 8 significantly inhibits RIP3-RIP1-kinase-dependent necroptosis in line with the activation of death receptor $(8,16)$. At the molecular level, caspase- 8 is observed to proteolytically cleave and inactivate RIP1 and RIP3, thereby controlling RIP-3-mediated necrosis. In the present study, the expression of TNFR1 and RIP3 was measured in rat brains subjected to MCAO. This demonstrated that TNFR1 and RIP3 were significantly upregulated, suggesting that inflammation-induced cell necrosis occurs following CIRI. However, pre-administration with zVAD significantly increased the protein level of RIP3, with no effect on TNFR1, accompanied by enhanced cell necrosis. These results suggest that zVAD mediates caspase-independent cell death. Thus, the inhibition of caspase- 8 using zVAD may sensitize cerebral cells to RIP-mediated necroptotic cell death following IR. Taken together, RIP3-mediated cell necrosis may be enhanced by caspase blockade using zVAD, and the function of zVAD is indicated to be independent of TNFR1 signaling following IR.

\section{Acknowledgements}

The current study was supported by the Natural Science Foundation of Liaoning Province (grant no. 2014022008).

\section{References}

1. Cerqueira NF, Hussni CA and Yoshida WB: Pathophysiology of mesenteric ischemia/reperfusion: A review. Acta Cir Bras 20: 336-343, 2005.

2. Takahashi H, Xia P, Cui J, Talantova M, Bodhinathan K, Li W, Holland EA, Tong G, Piña Crespo J, Zhang D et al: Pharmacologically targeted NMDA receptor antagonism by NitroMemantine for cerebrovascular disease. Sci Rep. 5: $14781,2015$.

3. Granger DN and Kvietys PR: Reperfusion injury and reactive oxygen species: The evolution of a concept. Redox Biol 6: 524-551, 2015.

4. Xu M, Chen X, Gu Y, Peng T, Yang D, Chang RC, So KF, Liu K and Shen J: Baicalin can scavenge peroxynitrite and ameliorate endogenous peroxynitrite-mediated neurotoxicity in cerebral ischemia-reperfusion injury. J Ethnopharmacol 150: 116-124, 2013.

5. Wang J, Wang P, Li S, Wang S, Li Y, Liang N and Wang M: Mdivi-1 prevents apoptosis induced by ischemia-reperfusion injury in primary hippocampal cells via inhibition of reactive oxygen species-activated mitochondrial pathway. J Stroke Cerebrovasc Dis 23: 1491-1499, 2014.

6. Van Herreweghe F, Festjens N, Declercq W and Vandenabeele P: Tumor necrosis factor-mediated cell death: To break or to burst, that's the question. Cell Mol Life Sci 67: 1567-1579, 2010.

7. Xanthoulea S, Pasparakis M, Kousteni S, Brakebusch C, Wallach D, Bauer J, Lassmann H and Kollias G: Tumor necrosis factor (TNF) receptor shedding controls thresholds of innate immune activation that balance opposing TNF functions in infectious and inflammatory diseases. J Exp Med 200: 367-376, 2004.

8. He S, Wang L, Miao L, Wang T, Du F, Zhao L and Wang X: Receptor interacting protein kinase-3 determines cellular necrotic response to TNF- $\alpha$. Cell 137: 1100-1111, 2009.

9. Li J, McQuade T, Siemer AB, Napetschnig J, Moriwaki K, Hsiao YS, Damko E, Moquin D, Walz T, McDermott A, et al: The RIP1/RIP3 necrosome forms a functional amyloid signaling complex required for programmed necrosis. Cell 150: 339-350, 2012.

10. Wu W, Liu P and Li J: Necroptosis: An emerging form of programmed cell death. Crit Rev Oncol Hematol 82: 249-258, 2012

11. Cho YS, Challa S, Moquin D, Genga R, Ray TD, Guildford M and Chan FK: Phosphorylation-driven assembly of the RIP1-RIP3 complex regulates programmed necrosis and virus-induced inflammation. Cell 137: 1112-1123, 2009.

12. Kaiser WJ, Upton JW, Long AB, Livingston-Rosanoff D, Daley-Bauer LP, Hakem R, Caspary T and Mocarski ES: RIP3 mediates the embryonic lethality of caspase-8-deficient mice. Nature 471: 368-372, 2011.

13. Vandenabeele P, Declercq W, Van Herreweghe F and Vanden Berghe T: The role of the kinases RIP1 and RIP3 in TNF-induced necrosis. Sci Signal 3: re4, 2010.

14. Moriwaki K and Chan FK: RIP3: A molecular switch for necrosis and inflammation. Genes Dev 27: 1640-1649, 2013.

15. Zhang DW, Zheng M, Zhao J, Li YY, Huang Z, Li Z and Han J: Multiple death pathways in TNF-treated fibroblasts: RIP3- and RIP1-dependent and independent routes. Cell Res 21: 368-371, 2011. 
16. Zhang DW, Shao J, Lin J, Zhang N, Lu BJ, Lin SC, Dong MQ and Han J: RIP3, an energy metabolism regulator that switches TNF-induced cell death from apoptosis to necrosis. Science 325: 332-336, 2009

17. National Research Council (USA) Institute for Laboratory Animal Research: Guide for the Care and Use of Laboratory Animals. 8th edition. National Academies Press (USA), Washington, DC, 1996.

18. Longa EZ, Weinstein PR, Carlson S and Cummins R: Reversible middle cerebral artery occlusion without craniectomy in rats. Stroke 20: 84-91, 1989.

19. Thored P, Wood J, Arvidsson A, Cammenga J, Kokaia Z and Lindvall O: Long-term neuroblast migration along blood vessels in an area with transient angiogenesis and increased vascularization after stroke. Stroke 38: 3032-3039, 2007.

20. Swanson RA, Morton MT, Tsao-Wu G, Savalos RA, Davidson C and Sharp FR: A semiautomated method for measuring brain infarct volume. J Cereb Blood Flow Metab 10: 290-293, 1990.

21. Kim SJ and Li J: Caspase blockade induces RIP3-mediated programmed necrosis in Toll-like receptor-activated microglia. Cell Death Dis 4: e716, 2013.

22. Durai Pandian J, Padma V, Vijaya P, Sylaja PN and Murthy JM: Stroke and thrombolysis in developing countries. Int J Stroke 2: 17-26, 2007.

23. Xu D, Du W, Zhao L, Davey AK and Wang J: The neuroprotective effects of isosteviol against focal cerebral ischemia injury induced by middle cerebral artery occlusion in rats. Planta Med 74: 816-821, 2008.

24. Budohoski KP, Guilfoyle M,Helmy A,Huuskonen T, Czosnyka M, Kirollos R, Menon DK, Pickard JD and Kirkpatrick PJ: The pathophysiology and treatment of delayed cerebral ischaemia following subarachnoid haemorrhage. J Neurol Neurosurg Psychiatry 85:1343-1353, 2014.

25. Xu H, Zhang Y, Sun H, Chen S and Wang F: Effects of acupuncture at GV20 and ST36 on the expression of matrix metalloproteinase 2, aquaporin 4, and aquaporin 9 in rats subjected to cerebral ischemia/reperfusion injury. PLoS One 9: e97488, 2014.

26. Chen HJ, Shen YC, Shiao YJ, Liou KT, Hsu WH, Hsieh PH, Lee CY, Chen YR and Lin YL: Multiplex Brain Proteomic Analysis Revealed the Molecular Therapeutic Effects of Buyang Huanwu Decoction on Cerebral Ischemic Stroke Mice. PLoS One 10: e0140823, 2015.

27. Li W, Tan C, Liu Y, Liu X, Wang X, Gui Y, Qin L, Deng F, $\mathrm{Yu} \mathrm{Z}, \mathrm{Hu} \mathrm{C}$, and Chen L: Resveratrol ameliorates oxidative stress and inhibits aquaporin 4 expression following rat cerebral ischemia-reperfusion injury. Mol Med Rep 12: 7756-7762, 2015.
28. Saini MK, Sanyal SN and Vaiphei K: Piroxicam and C-phycocyanin mediated apoptosis in 1,2-dimethylhydrazine dihydrochloride induced colon carcinogenesis: Exploring the mitochondrial pathway. Nutr Cancer 64: 409-418, 2012.

29. Günther C, Martini E, Wittkopf N, Amann K, Weigmann B, Neumann H, Waldner MJ, Hedrick SM, Tenzer S, Neurath MF and Becker C: Caspase- 8 regulates TNF- $\alpha$-induced epithelial necroptosis and terminal ileitis. Nature 477: 335-339, 2011.

30. Bamias G, Jia LG and Cominelli F: The tumor necrosis factor-like cytokine $1 \mathrm{~A} /$ death receptor 3 cytokine system in intestinal inflammation. Curr Opin Gastroenterol 29: 597-602, 2013.

31. Ma J, Endres M and Moskowitz MA: Synergistic effects of caspase inhibitors and MK-801 in brain injury after transient focal cerebral ischaemia in mice. Br J Pharmacol 124: 756-762, 1998.

32. Madsen PM, Clausen BH, Degn M, Thyssen S, Kristensen LK, Svensson M, Ditzel N, Finsen B, Deierborg T, Brambilla R, Lambertsen KL. Genetic ablation of soluble tumor necrosis factor with preservation of membrane tumor necrosis factor is associated with neuroprotection after focal cerebral ischemia. J Cereb Blood Flow Metab. Oct 19, 2015 (Epub ahead of print).

33. Xu Y, Wang J, Song X, Wei R, He F, Peng G and Luo B: Protective mechanisms of CA074-me (other than cathepsin-B inhibition) against programmed necrosis induced by global cerebral ischemia/reperfusion injury in rats. Brain Res Bull 120: 97-105, 2016.

34. Moulin M, Anderton H, Voss AK, Thomas T, Wong WW, Bankovacki A, Feltham R, Chau D, Cook WD, Silke J and Vaux DL: IAPs limit activation of RIP kinases by TNF receptor 1 during development. EMBO J 31: 1679-1691, 2012.

35. Degterev A, Huang Z, Boyce M, Li Y, Jagtap P, Mizushima N, Cuny GD, Mitchison TJ, Moskowitz MA and Yuan J: Chemical inhibitor of nonapoptotic cell death with therapeutic potential for ischemic brain injury. Nat Chem Biol 1: 112-119, 2005.

36. Yeh WC, Itie A, Elia AJ, Ng M, Shu HB, Wakeham A Mirtsos C, Suzuki N, Bonnard M, Goeddel DV and Mak TW: Requirement for Casper (c-FLIP) in regulation of death receptor-induced apoptosis and embryonic development. Immunity 12: 633-642, 2000.

37. Boise LH, Minn AJ, Noel PJ, June CH, Accavitti MA, Lindsten $\mathrm{T}$ and Thompson CB: CD28 costimulation can promote $\mathrm{T}$ cell survival by enhancing the expression of Bcl-XL. Immunity 3: 87-98, 1995.

38. Oberst A, Dillon CP, Weinlich R, McCormick LL, Fitzgerald P, Pop C, Hakem R, Salvesen GS and Green DR: Catalytic activity of the caspase-8-FLIP(L) complex inhibits RIPK3-dependent necrosis. Nature 471: 363-367, 2011. 